NBER WORKING PAPER SERIES

\title{
EFFICIENT WAGE BARGAINS UNDER UNCERTAIN SUPPLY AND DEMAND
}

\author{
Robert E. Hall \\ and \\ David M. Lilien \\ Working Paper No. 306 \\ NATIONAL BUREAU OF ECONOMIC RESEARCH \\ 1050 Massachusetts Avenue \\ Cambridge MA 02138 \\ December 1978
}

This research was supported by the National Science Foundation. We are grateful to Jerome Culp, Avinash Dixit and Jeffrey Harris for useful suggestions.

The research reported here is part of the National Bureau of Economic Research's research program in Economic Fluctuations. Any opinions expressed are those of the authors and not those of the National Bureau of Economic Research. 
EFFICIENT WAGE BARGAINS UNDER UNCERTAIN SUPPLY AND DEMAND

by

Robert E. Hall and David M. Lilien

\section{$\underline{\text { Abstract }}$}

This paper examines efficient arrangements between employers and workers for handling shifts in the demand for and supply of labor. Efficiency is achieved when the marginal revenue product of labor equals the marginal value of time. The problem is to set up contractual provisions so that employment can vary as supply and demand change. Where the shifts are observable and outside the control of the parties to the contract, a fully contingent contract can achieve efficiency. However, these conditions are rarely met in practice and contingent labor contracts, apart from cost of living escalators, are almost never found. The paper investigates non-contingent contracts that are efficient or approximately efficient. It shows the impossibility of full efficiency in the face of shifts in both supply and demand and the feasibility of efficiency when only demand or only supply shift. It argues that very nearly efficient contracts are possible when demand shifts are much larger than supply shifts, and shows that the type of contract appropriate for this case bears strong resemblance to collective bargaining agreements in the United States. In particular, it shows that the current state of demand should be completely irrelevant in the process of renegotiating a labor contract.

Robert E. Hall

National Bureau of Economic Research 204 Junipero Serra Boulevard Stanford, CA 94305 
EFFICIENT WAGE BARGAINS UNDER UNCERTAIN SUPPLY AND DEMAND $†$

Robert E. Ha1l and David M. Lilien*

Much recent thought has been devoted to the macroeconomic importance of the existence of wage contracts ${ }^{1}$ and to the deeper problem of the nature of the optimal employment bargain. ${ }^{2}$ Still, some puzzling features of the most conspicuous form of wage bargaining, that done formally by employers and labor unions, deserve further theoretical attention. Among these important features are:

1. Collective bargaining agreements are rarely contingent on outside events even though the parties have very imperfect knowledge of prospective economic conditions during the period of the contract. The only important exception is the indexing of wages to the cost of living.

2. Employers are permitted wide discretion in determining the level of employment when demand shifts unexpectedly. As employment varies, total compensation varies according to a formula established in the agreement.

3. Agreements are not permanent but are renegotiated on a regular cycle.

4. In the process of renegotiation, the current state of demand has little impact on the new wage schedule. On the other hand, current wages in other industries have an important influence.

The last feature especially has been denied or ignored by economic theorists even though it is a prominent part of the thinking of labor economists on wage determination. 


\section{The employment bargain}

Since Wassily Leontief's classic paper, it has been known that employers and workers must agree on more than just an hourly wage. In bargaining under certainty, there is a presumption that the bargain establishes a level of employment as well as a level of compensation. A review of this case will help to establish some concepts that are useful when bargainers are grappling with uncertainty as well. First, let the technology of the firm and the demand function for its products be jointly summarized by a revenue function, $R(L)$, giving gross dollar revenue as a function of total labor input, L. We assume; as seems appropriate in the context of collective bargaining, that the firm has some monopoly power. Second, let $V(L)$ be the labor union's opportunity cost of supplying that amount of labor, in the sense of foregone consumer surplus from diverting leisure to work, or foregone earnings from other employment. $V(L)$ can be thought of as the minimum offer that the union would ever accept to supply L. ${ }^{3}$ We do not pursue the question of how the union divides $\mathrm{L}$ among its members, nor the way that it allocates the proceeds of the sale of L. If the union members have identical preferences and identical alternative employment opportunities and if the union allocates work and income evenly then $\mathrm{V}(\mathrm{L})$ simply represents the typical union member. Our results are compatible with many other views of the internal politics of unions, however.

Labor input, $L$, is one dimension of the bargaining problem. The other is dollar compensation. It is most convenient to deal with total compensation or the wage bill, say $B$, rather than with the more familiar average hourly wage. The firm's concern is with profit, $\pi=R(L)-B$, and the union's concern is with income net of the opportunity cost of the time devoted to work, $\mathrm{Y}=\mathrm{B}-\mathrm{V}(\mathrm{L})$. The bargaining problem is illustrated in Figure 1. The 
Figure I

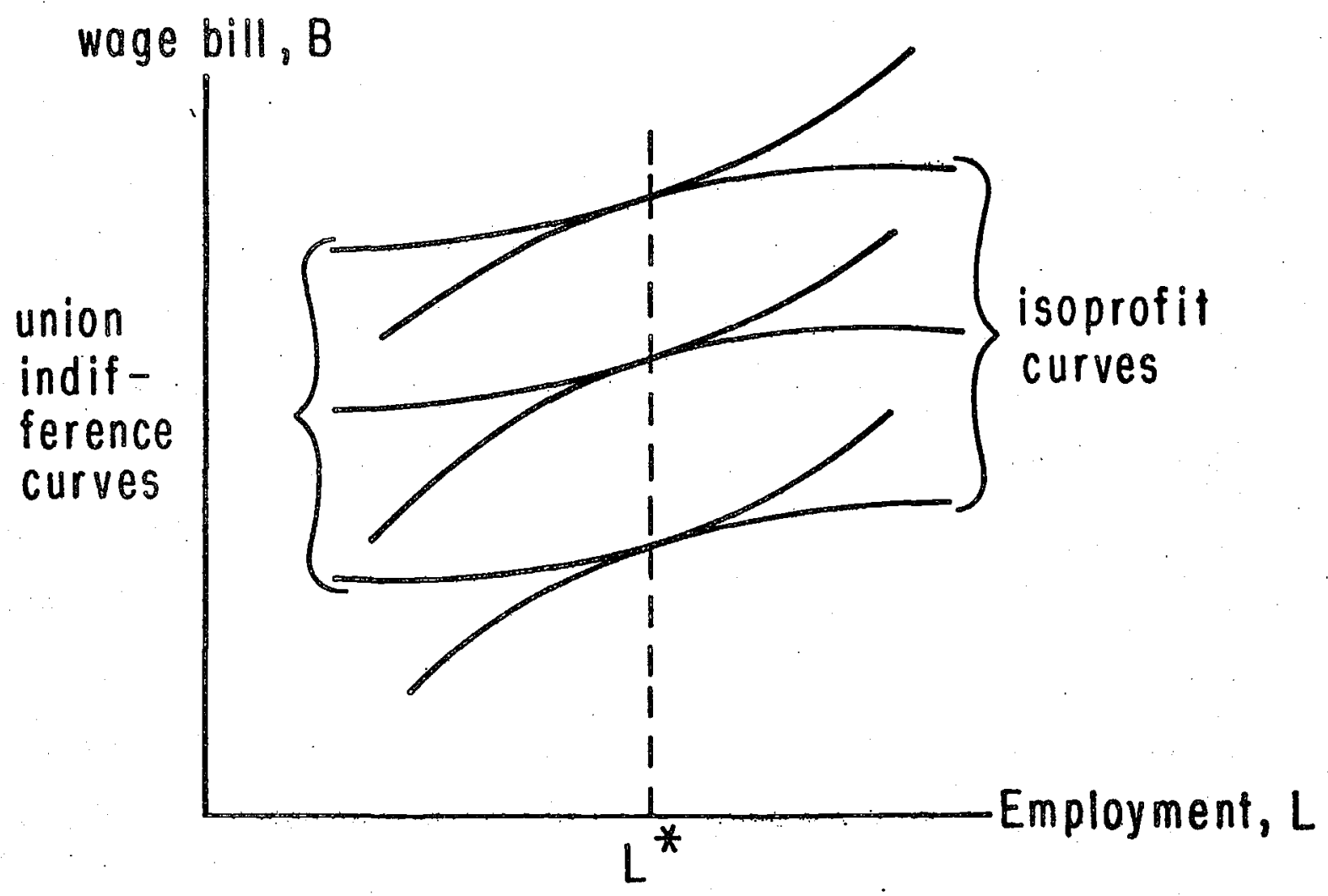


contract curve, or set of alternative efficient bargains, is the vertical line, $L=L^{*}{ }^{4}$ Each point on the line satisfies the basic efficiency requirement that the marginal revenue product of labor, $R^{\prime}(L)$, equals the marginal opportunity cost of work, $\mathrm{V}^{0}(\mathrm{~L})$. We assume that cooperative bargainers will always strike a bargain that is efficient. The major issue in bargaining is the determination of the wage bill, that is, the splitting of monopoly profits between firm and union. Most theoretical work on collective bargaining has concerned this very difficult issue. ${ }^{5}$ We will avoid it altogether. Our interest is in describing efficient bargains, and in the case of complete certainty, the answer is straightforward - a bargain is efficient only if it sets a level of employment at $L^{*}$.

As Leontief pointed out, the efficient bargain cannot generally be supported by agreeing on an average wage, $w=B / L$, and then letting the firm maximize profit subject to this wage. Profit maximization sets the marginal revenue product of labor to the wage, while an efficient bargain requires that it equal the marginal opportunity cost of work. Only by coincidence would they be the same. Figure 2 illustrates the point. Suppose bargaining settled on the efficient point $A$. The slope of the line $O A$ is the implicit average wage, and the line itself is the set of employment levels and wage bills that the firm would choose among if it maximized profit subject to the average wage. The point of maximum profit is $A^{p}$, where $O A$ is tangent to an isoprofit curve, and profit here is necessarily higher than at $A$. So the collective bargaining agreement must specify the level of employment as we11 as the total compensation or average wage. Alternatively, the bargainers may use some other mechanism to ensure efficiency.

Most employers have wide latitude in setting the level of employment. It is interesting to ask whether there are contractual arrangements that 
Figure 2

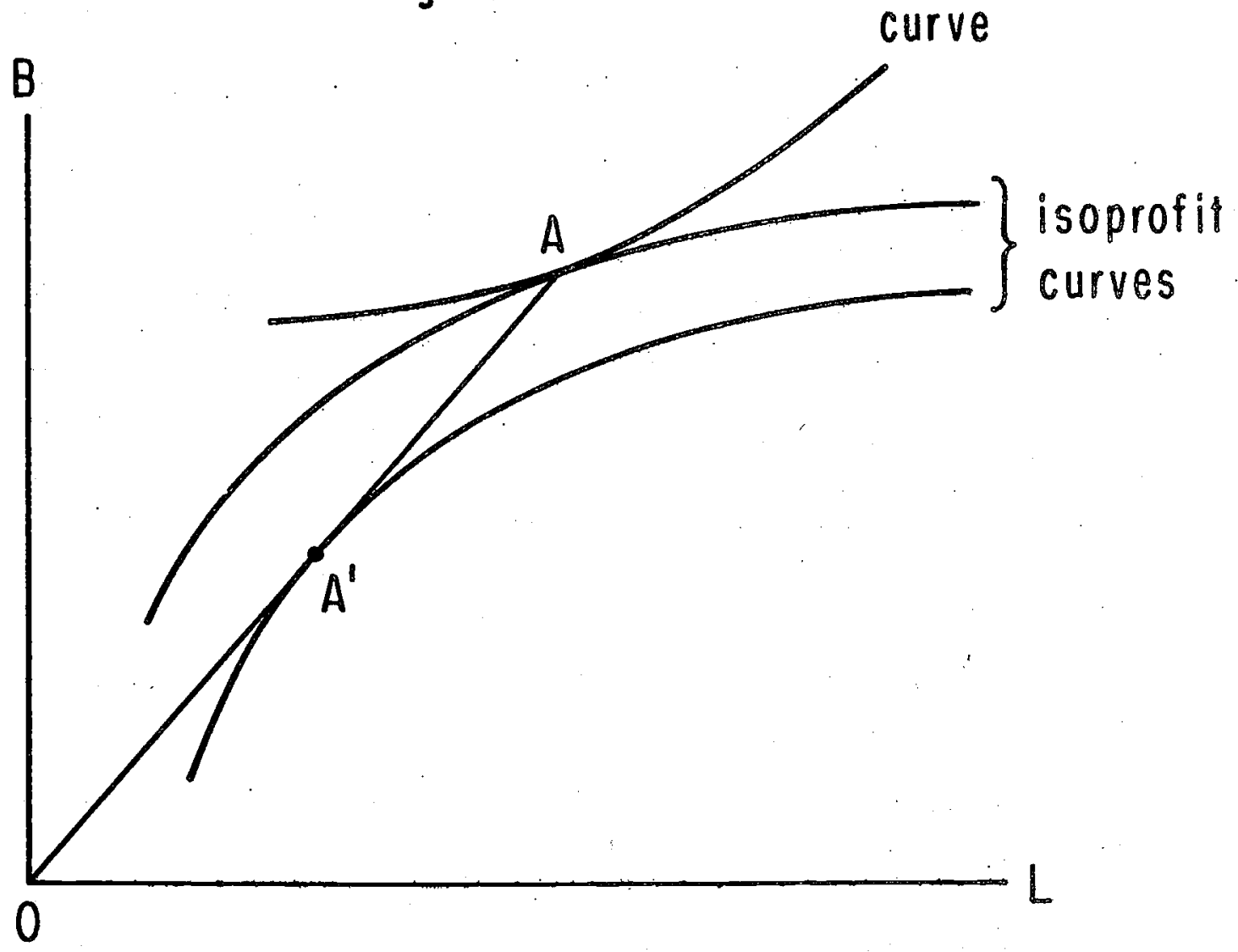


achieve efficiency while permitting unilateral profit maximization by the firm. In particular, we ask if there is a way to make the wage bill a function of employment, say $B(L)$, so that maximization of profit, $\pi(L)=$ $R(L)-B(L)$ occurs at the efficient level of employment, $L^{*}$. In fact, there is an infinite variety of such arrangements. Any compensation rule is satisfactory if the marginal cost of labor to the firm $B^{\prime}(L)$ equals the marginal opportunity cost of labor, $V^{*}(L)$, at the efficient level of employment, $L^{*}$. To avoid the possibility that this point is a minimum instead of a maximum, and to eliminate multiple local maxima, we will also require that the marginal cost of labor, $B^{\prime}(L)$, be an increasing function. of L. Then as an alternative to stating the bargain as a particular level of employment and a particular amount of compensation, bargainers may arrive at a compensation rule $B(L)$ instead, and let firms choose employment unilaterally subject to the rule. This way of expressing the outcome of bargaining seems closer to the actual practice in American collective bargaining.

\section{Efficient wage bargains under uncertainty}

Neither party to a collective bargaining agreement has full knowledge of the economic circumstances that will prevail during the agreement. Both the demand for products and the opportunity cost of labor can change unexpectedly. Framers of agreements must anticipate the possible need to adjust the level of employment as supply and demand change. Adjustments of employment are in fact made on a weekly schedule in most American industries.

Suppose that shifts in demand can be characterized by a single random variable, $x$, so that the revenue function is $R(L, x)$. Though we do not make any assumptions about the probability distribution of $x$, it is not necessarily a variable that moves around a normal level -- it may drift upward or downward. 
On the supply side, we hypothesize a similar random shift, $z$, in the opportunity cost of employment, $V(L, z)$. Again, $z$ captures general changes in the cost of living and in wages elsewhere in the economy, as well as conditions in labor markets close to the firm where union members might seek alternative employment.

For particular values of $x$ and $z$, the efficient level of employment is still defined by the equality of the marginal revenue product of labor and the marginal opportunity cost of the labor

$$
\frac{\partial R(L, x)}{\partial L}=\frac{\partial V(L, z)}{\partial L}
$$

This defines an efficient level of employment as a function of $\mathrm{x}$ and $\mathrm{z}$ : $L^{*}(x, z)$. The problem that concerns us in the remainder of this paper is contractual mechanisms that permit the level of employment to fluctuate exactly, or at least approximately, according to this function. Throughout, we assume that it is physically possible to adjust employment as supply and demand shift, so the relevant concept of efficiency is ex post. Because we seek contracts that are efficient in this sense no matter what random shifts have occurred, we make no assumptions about the probability distributions of $\mathbf{x}$ and $z$, nor do we assume that these distributions are known to the bargaining parties.

One class of contracts achieves efficiency ex post exactly for any values of $\mathrm{x}$ and $\mathrm{z}$. In these contracts, the level of employment is made contingent upon the values of the random shifts. The employment part of the bargain is then a function of $x$ and $z$, and the bargain is efficient only if the function is $L^{*}(x, z)$. As in the case of certainty, the hard part of the bargaining process is settling upon a distribution of monopoly profits. Now this must 
be done separately for each possible contingency, by establishing a contingent wage bill, $B(x, z)$.

Important practical obstacles limit the scope of contingent contracts. One of these is the need to measure the variables describing the contingency quickly and accurately, and to avoid costly legal disputes about the measurements. Government statistics of high quality, such as the Consumer Price Index, are acceptable for this purpose, but many other kinds of data, publicly or privately collected, probably are not. Making contracts involving millions or billions of dollars contingent on a particular statistic obviously puts immense strain on the collectors of the statistic. The second practical obstacle is moral hazard. If the contract is contingent upon variables that can be influenced by one of the parties to the contract, they will face an incentive to change the variable accordingly. ${ }^{6}$ The existence of moral hazard does not preclude the use of contingent contracts. It may simply be accepted as an inevitable source of inefficiency, as for example in the case of automobile insurance where insured drivers presumably are not quite as careful as they should be.

As an extreme case of the problem of moral hazard, suppose that there are no genuine shifts in demand, but the bargainers agree upon a contingent contract providing employment, $L^{*}(x, z)$, and compensation, $B(x, z)$. Management can in fact announce any value of $x$ they please. Then the contract effectively establishes a marginal cost of labor which is the change in compensation per unit change in employment, $(\partial \mathrm{B} / \partial \mathrm{x}) /(\partial \mathrm{L} * / \partial \mathrm{x})$. To maximize profit, management will choose the $\mathrm{x}$ that equates the marginal revenue product of labor to the implicit marginal cost of labor. Unless this has been foreseen by the bargainers, the resulting level of employment will not be efficient. For example, suppose that the compensation side of the bargain is a guaranteed 
annual wage, independent of demand and supply: $B(x, z)=B$, a constant. Then management can cheat by driving the marginal revenue product of labor down to the implicit cost of labor, namely zero, by a suitable overstatement of the level of demand. Conversely, if the compensation rule were quite sensitive to demand, management would have an incentive to understate demand in order to reduce labor input.

Cheating of this kind does not seem to be an important problem in American labor relations. Rather, both parties agree from the beginning that management is free to maximize profit under the terms of the contract. There are no outside demand variables, supposedly beyond the control of the firm, upon which the collective bargaining agreement is contingent.

Similar considerations limit the usefulness of contingent bargains on the supply side. A reliable government cost of living index is published in the United States, and many agreements are contingent upon it. Much less reliable, but highly relevant data on hourly wages are also published, but we are unaware of any formal contingencies based on wages. Many of the same obstacles limit the use of outside variables to measure shifts in the opportunity cost of labor as limit the use of demand variables. In the rest of this paper, therefore, we assume th山t contracts cannot simply specify employment as a function $L^{*}(x, z)$ and compensation as $B(x, z)$. More subtle procedures for achieving efficiency are required.

III. Efficient contracts that are not contingent on outside variables Bargainers who are wary of making agreements contingent upon outside measures of demand and supply nonetheless have a powerful tool at their disposal for achieving efficiency ex post: They can make the level of compensation contingent upon the actual level of employment. ${ }^{7}$ of all the 
data that might be supplied by the firm to the union, the level of employment is most easily verified by the union. However, since both parties have a direct influence over the amount of employment, bargainers presumabiy must accept the constraint that both management and labor will separately try to maximize we11-being by adjusting the level of employment. 8 This situation would breed a tension of its own unless the provisions of the contract are such as to make both parties agree on the desirable level of employment ex post. 9

The collective bargaining agreement we study here establishes a compensation rule, $B(L)$, not directly contingent upon the demand and supply shifts $x$ and $z$. The firm has profit, $R(L, x)-B(L)$, and the union has we11being, $B(L)-V(L, z)$. The efficient level of employment is the same $L^{*}(x, z)$ defined earlier. We ask: Is there a compensation rule under which the quantity of labor demanded by management, derived from

$$
\frac{\partial R(L, x)}{\partial L}=B^{0}(L) \text {, }
$$

is equal to the quantity of labor supplied by the union, derived from

$$
\frac{\partial V(L, z)}{\partial L}=B^{\prime}(L)
$$

for all possible $x$ and $z$ ? Under such a compensation rule, management and labor will never disagree about the desirable level of employment. In particular, there is no danger of default by either party to the contract. Furthermore, a compensation rule that achieves agreement in this sense is automatically efficient ex post. Since $\partial R / \partial L$ and $\partial V / \partial L$ are both equated to the same $B^{\prime}(L)$, they equal each other, and this is the definition of efficiency. 
Compared to the full contingent bargain discussed in the previous section, only one major restriction limits the ideal employment-contingent contract: The distribution of monopoly profit cannot be made separately contingent on shifts in demand and supply. The shape of $B(L)$ is determined by the efficiency requirement alone. As $\mathrm{L}$ shifts, the distribution of monopoly profits shifts as a byproduct of the shape of the compensation rule. The bargainers retain the single most important distributional tool -- they are free to determine the overall level of $B(L)$ by adding a constant to it. Efficiency depends only on the marginal rate of compensation $B^{\prime}(L)$ and not on its level. But the ideal employment-contingent contract is incapable of insuring workers against fluctuations in income, unless $B(L)$ provides the appropriate amount of insurance. ${ }^{10}$

Under the most general conditions, the ideal employment-contingent compensation rule does not exist. A fixed relation between compensation and employment does not have enough degrees of freedom, so to speak, to achleve efficiency under all possible combinations of demand and supply shifts. This proposition is formalized and proved in the Appendix.

Ideal compensation rules do exist under more restrictive conditions. First, suppose that there are no uncertainties about the opportunity cost on the supply side, or, more realistically, all uncertainties can be eliminated through the use of a cost-of-living escalator. Then $V(L, z)$ is just $V(L)$. The ideal compensation rule satisfies

$$
\frac{\partial R(L, x)}{\partial L}=B^{*}(L), \text { all } x \text {, and }
$$

$$
V^{p}(L)=B^{p}(L)
$$


The second equation suggests the nature of the ideal rule. Firms should be made to internalize labor's opportunity costs by paying a marginal cost of labor, $B^{\prime}(\mathrm{L})$, which always equals labor's marginal opportunity cost, $V^{\prime}(L)$. In other words, the compensation rule has the form

$$
B(L)=B_{0}+V\left(L_{1}\right)
$$

$B_{0}$ is a fixed cash payment to labor which is independent of the amount of work and is chosen by the negotiators in the light of puxely distributional. considerations. Again, we have nothing to say about $B_{Q}$, but any value of $B_{0}$ is consistent with efficlency. Under this compensation rulle, the well-being of the union is

$$
\begin{aligned}
B(L)-V(L) & =B_{0}+V(L)-V(L) \\
& =B_{0},
\end{aligned}
$$

a constant Independent of L. Labor never disagrees with management about $\mathrm{L}$ because it is indifferent among all levels of employment. Rather than a guaranteed annual wage, labor has a guaranteed annual level of well-being. Management alone knows the true level of demand, measured by $x$, and makes a unilateral decision about employment. The level chosen is efficient because of the internalization of labor's opportunity costs by management. The absence of contractual limitations on employer's rights to vary employment is one of the four major features of American collective bargaining that we set out to explain. In that respect, contracts where the compensation rule embodies the opportunity cost of labor's time may be realistic. ${ }^{11}$

At the opposite extreme, suppose that demand is known in advance, so that the revenue function is just $R(L)$, but random shifts in the supply side 
make labor 's opportunity cost depend on $z$ : $V(L, z)$. An ideal compensation rule then satisfies

$$
\begin{aligned}
R^{D}(L) & =B^{\prime}(L) \\
\frac{\partial V(L, z)}{\partial L} & =B^{P}(L) 。
\end{aligned}
$$

Again, such a rule exists for this case, but now it has an entirely unfamiliar flavor. Compensation must be total revenue less a distributive constant:

$$
B(L)=R(L)-B_{0}
$$

Profit is

$$
\begin{aligned}
\pi(L) & =R(L)-B(L) \\
& =B_{0},
\end{aligned}
$$

so management is indifferent among all levels of employment. Labor Internalizes the production function and product demand functions and unilatexally determines employment to maximize its "profit," $R(L)-V(L, z)-B_{0}$ " No collective bargaining agreement known to us provides that the union makes the employment decision and management acquiesces passively, even though this kind of contract seems a theoretical possibility.

The striking difference between the two cases makes it clear why an ideal employment-contingent contract does not exist when both demand and supply shift randomly. To achieve efficiency in the face of demand shifts, the marginal rate of compensation, $B^{\prime}(L)$, must increase with $L$, as it reflects the increasing marginal opportunity cost of labor. But to achieve efficiency In the face of supply shifts, $B^{\prime}(L)$ must decrease with $L$, because the marginal revenue product of labor is a decreasing function. The two requirements are 
contradictory. The contradiction is also apparent between the administrative arrangements that support the two kinds of contracts. One or the other party, but not both, must set employment unilaterally.

One other special case will prove useful for the ensuing discussion. Suppose that both supply and demand shift, but that the two shifts are related. Specifically, let

$$
z=f(x)
$$

The conditions for an ideal compensation rule are

$$
\begin{array}{r}
\frac{\partial R\left(L_{2} x\right)}{\partial L}=B^{\prime}(L) \\
\frac{\partial V(L, f(x))}{\partial L}=B^{\prime}(L)
\end{array}
$$

These define the efficient level of employment as a function, $L^{*}(x)$, of the random shift. The most interesting and relevant case is where the shift raises the marginal revenue product of labor and raises the marginal opportunity cost of labor, but the former predominates so the efficient level of employment rises when $x$ rises. For example, this would describe a cyclically-sensitive industry where $\mathrm{x}$ is a measure of aggregate demand.

In this case the ideal compensation rule exists but does not have a closed mathematical form. On the margin, it can be described in the following way. Let $x(L)$ be the value of the random shift for which $L$ is the efficient level of employment (the inverse of $L^{*}(x)$ ). Then

$$
B^{\prime}(L)=\frac{\partial V(L, f(x(L)))}{\partial L}
$$

or, 


$$
B(L)=B_{0}+\int_{0}^{L} \frac{\partial V(L, f(x(L)))}{\partial L} d L
$$

$\mathrm{B}_{\mathrm{O}}$ is a purely distributional parameter, as before. The principle remains that marginal compensation should equal the marginal opportunity cost of labor, but now the opportunity cost must be evaluated at the value of the supply shift, $z$, corresponding to the demand shift, $x$. Under our assumptions, the dependence of the supply shift on the demand shift has a particular implication about the shape of $B(L)$ : Marginal compensation rises more ' sharply with $\mathrm{L}$ than does the marginal opportunity cost of 1abor.

Under the ideal compensation rule, management determines employment unilaterally by setting $L$ to satisfy profit maximization:

$$
\frac{\partial R(L, x)}{\partial L}=B^{\prime}(L)
$$

It is interesting to compare the response of employment to a change in $x$ in this case to the response when supply is unaffected by $x$. In the present case, where the compensation rule takes account of related shifts in supply, the steeper marginal compensation schedule acts to limit employment fluctuations. The logic is straightforward-- if demand shocks are accompanied by offsetting supply shocks, then the efficient change in employment is smaller than it would be if supply were unrelated. An important special case of this proposition has been pointed out by Robert Barro: Purely monetary disturbances generate exactly offsetting shifts in supply and demand and leave the efficient level of employment unchanged. If collective bargaining achieves efficiency ex post, then monetary disturbances should have no effect on employment even within the span of labor contracts. This is a major criticism of existing contract theory, which frequently claims to explain the 
apparent sensitivity of employment to monetary disturbances. We will return to this point at the conclusion of the paper.

\section{Approximately efficient contracts}

When both demand and supply are uncertain, ideal employment-contingent compensation rules do not exist. Collective bargainers seem to deal with this problem in the following way: Approximately efficient contracts are adopted that preserve efficiency in the face of the most likely source of large fluctuations. The contracts have a finite duration, almost always three years. 12 At the time of renegotiation, events that have caused the previous contract to become inefficient can be taken into account. An important feature of this approach to collective bargaining is the irrelevance at renegotiation of events which have already been accommodated within the existing contract. To the extent that the previous contract was successful in establishing a framework for adapting to the major contingencies, only minor contingencies will remain to be accommodated. To the naive observer, then, collective bargainers will appear to be preoccupied with trivial issues and to ignore what is most important. In particular, we believe this accounts for the strong belief among many economists that collective bargainers are perverse and irrational in failing to let the wage respond appropriately to changes in demand. We will argue that, to a first approximation, the state of demand should be irrelevant to rational collective bargainers.

We begin with the hypothesis that the stochastic natures of unexpected fluctuations in demand and in supply are rather different. The demand for the products of a single firm fluctuates with large amplitude, and some, but not a11, of the fluctuations are transitory. Many demand shifts are unrelated to fluctuations in aggregate demand. On the other hand, fluctuations in the 
opportunity cost of labor are relatively small and are closely related to developments elsewhere in the economy, especially unexpected changes in average wages and prices and in the availability of work in neighboring markets. When these changes occur, they are frequently permanent. Some of the fluctuations in demand and supply are related-- for example, an increase in aggregate demand raises both the demand for the firm's product and the opportunity cost of the labor it uses. But the correlation on this account is weak. Most fluctuations in demand are unrelated to aggregate demand, and although these fluctuations are invisible in aggregate statistics, they are crucial in designing an efficient labor contract.

Collective bargainers choose between two very different types of contracts in designing an approximately efficient bargain. They may establish a compensation rule based on expectations about the opportunity cost of labor, and let management choose the level of employment unilaterally in view of their perceptions of demand. Alternatively, the compensation rule may be based on expectations of the level of product demand, and 1abor given the task of determining the level of employment unilatera1ly in response to supply conditions. The first type is efficient for demand fluctuations and the second for supply fluctuations. Neither is ideal. There is no way to compromise between them without creating some kind of joint decision-making body to determine the level of employment.

Under our hypotheses about the nature of fluctuations in demand and supply, it is apparent that the first type of contract will be adopted by the bargainers. The dominant source of potential inefficiency over the life of a three-year contract is demand fluctuations. But supply fluctuations need not be completely ignored. To the extent that supply and demand shifts are correlated, management can be induced to treat the demand shift as a signal 
of a supply shift as we11. Suppose that the supply variable, $z$, can be decomposed into a part that is predictable from the demand variable, say $f(x)$, and an unpredictable residual, z̃:

$$
z=f(x)+\tilde{z}
$$

Under these conditions, an approximately efficient contract can be drawn along the lines suggested in the previous section. The marginal rate of compensation should be

$$
B^{\prime}(L)=\frac{\partial V(L, f(x(L)))}{\partial L}
$$

The resulting contract will be exactly efficient in the face of any demand shift that is accompanied by the typical supply shift. Again, if the efficient level of employment rises with rising demand and if supply shifts away from the firm, typically, when demand rises, then the compensation rule based on this principle will result in more stable employment than will a rule based only on demand shifts. This stabilization is achieved by making it financially unattractive to management to make large adjustments in employment, not by prohibiting them.

\section{Institutional aspects}

We have been deliberately vague up to this point about the mechanisms used to achieve the variations in employment that are needed to preserve efficiency. Members of effective labor unions are strongly attached to their jobs because the union obtains a share of the monopoly profit for them, so it is implausible that variations in our $L$ are achieved by changing the number of job-holders. Our apparatus is based on the contrary assumption that 
variations in $\mathrm{L}$ are achieved by changes in the amount of work done by a fixed group of union members. Part of these variations correspond to the wel1understood process of changing weekly hours of work in response to shifts in demand. But data on unionized industries show equally important fluctuations in employment. Why would a powerful union let one of its members lose his job? If decreases in $L$ are brought about by discharging union members, and subsequent increases in $\mathrm{L}$ are achieved by hiring new workers from the labor market at large, then the union is failing in its task of protecting the interests of its members.

The answer to this puzzle seems to lie in the hypothesis that relatively few of the people who stop working when demand falls actually lose their jobs. Reductions in employment are achieved by layoffs, and workers who are laid off are generally recalled after a matter of weeks or months and resume their old jobs. ${ }^{13}$ This process takes place even at normal levels of demand, so reduced layoff rates and faster recall are methods for increasing $L$ when demand is strong, as well. In other words, an important method for varying $\mathrm{L}$ is to change the annual weeks of work of a fixed labor force. In some industries, notably automobiles, this is accomplished by laying off the workers in entire plants for single weeks whenever output threatens to exceed demand. In other industries, layoffs are more selective and last longer for each individual.

The compensation rules suggested by our analysis make the marginal rate of compensation a fairly sensitive function of the level of employment. Management must pay a sharp premium to obtain unusually high levels of labor input, but escape very little of the obligation to pay compensation when they use low volumes of labor. The institutional arrangements that impose the disincentive to excess employment are, first, overtime premiums that require 
that marginal excess hours be paid at 50 percent above the average wage, 14 and, second, provisions that require the promotion of existing workers and limit new hires to entry levels. With respect to low levels of demand, the most obvious arrangement to depress the marginal rate of compensation is the supplementary unemployment benefit. The part of state-administered unemployment insurance that is experience-rated has the same effect. Further, some collective bargaining agreements, notably in the steel industry, provide that workers who are moved downward in the job ladder as a result of "bumping" are protected against the corresponding reduction in pay.

The evidence on compensation rules in American collective bargaining seems consistent with a marginal opportunity cost of labor schedule that rises fairly rapidly in the range of ful1-time work, though we emphasize that our theory predicts a more steeply rising marginal rate of compensation than marginal opportunity cost when demand and supply fluctuations are positively correlated. Empirical evidence on labor supply shows extreme sensitivity of the marginal opportunity cost of all labor supplied by an individual, in that estimated labor supply functions are virtually unresponsive to wages in the case of the adult men who are the bulk of union membership. However, the opportunity cost of all labor is not the same as the opportunity cost of labor supplied to the firm signing the collective bargaining agreement, since many union members hold second jobs or are able to find temporary work during periods of 1ayoff. For them, the marginal opportunity cost of work at the union job does not fall quickly to zero below full-time work. Similarly, the part of unemployment compensation that is not experience-rated makes time spent on layoff have a positive value to workers. All of these considerations make it desirable for the compensation rule to provide incentives to reduce employment in times of slack demand. 
VI. Risk and insurance

Efficient contracts expose workers to risk. Using the compensation schedule to make the employment-contingent contract efficient rules out the alternative of smoothing the variability of income by divorcing compensation from the level of employment. In this respect, our study is the polar opposite of most other work on labor contracts. Under the assumption of convenience adopted in the body of the paper that the marginal opportunity cost of labor does not depend on wealth, it turns out that the efficient contract does not expose the union to any risk at all-- the union is exactly compensated for the stochastic variation in employment arising from fluctuations in demand. But this is an artifact of our otherwise very convenient assumption. In general, the expected utility of the union could be increased by a set of insurance payments and premiums with expected value zero across the various possible levels of product demand. Were it not for the problems of moral hazard and unobservability of demand that limit the contracting process, either the firm or a private insurance company could sell insurance to the union. The work of Calvo and Phelps suggests that it is difficult to reach any definite conclusions about the optimal contract that balances efficiency against risk aversion. Rather than pursue the insurance side of labor contracts any further here, we will limit ourselves to listing the considerations that would make the insurance side particularly important :

1. If alternative levels of employment have large effects on wealth, then the need for insurance against them will be correspondingly 12rge. Thus, if union members have little income apart from compensation under the contract, and if the movements in employment that take place under the contract are permanent, then the optimal 
contract ill sacrifice a considerable amount of efficiency. On the other hand, if the movements are largely transitory, the need for insurance is reak and efficiency will be the dominant consideration in drawing the contract.

2. Insurance becomes important when the marginal opportunity cost of labor is sensitive to the level of wealth, or, to put it another way, the elasticity of labor supply to wealth is strongly negative. Research oa labor supply has shown quite weak income inelasticities for adult males.

3. Obviously, the demand for insurance depeads on the degree of risk aversion of the part of the union.

4. Finally, tie demand for insurance depends on the magnitude of the fluctuatioss that are likely to occur under the efficient contract. The incentre to insure against small fluctuations is weak.

VII. Macroeconomic isplications of efficient employment-contingent contracts

Labor contracts are of critical interest in macroeconomics because they seem to offer an exlanation for the persistence of unemployment. If wages are unresponsive to semeral economic conditions during the three years of a contract, then it Follows that wages cannot fully offset an aggregate disturbance until every contract has been renegotiated. This appears a more satisfying explanz=ion than the principal alternative where persistence is attributed to the slow diffusion of information in the labor market. ${ }^{15}$ But as Barro has point ב- out, purely nominal aggregate shocks, such as those caused by unexpect $\equiv d$ zonetary developments, have no effect on the efficient level of employmenz or uzemployment, and framers of labor contracts ought to be able to figure sut a way to avoid inefficient responses to these shocks. 
If all disturbances are purely nominal, then the efficient contract is extremely simple - it specifies a predetermined level of employment. The mere existence of labor contracts does not explain the persistence of unemployment satisfactorily.

Our discussion of the contracting problem at the level of the firm and the union suggests the di三ficulties in achieving the efficient response to an economy-wide disturbanze. Employment-contingent contracts seem a workable solution to the collectire bargaining problem at this level, but they embody a strong limitation on the response to aggregate disturbances. Only the part of the supply side of sucis a disturbance that can be predicted from the firm's own demand can be offset under the terms of the contract. If most fluctuations in demand at the level of the firm are unrelated to aggregate demand and thus are unrelated to changes in the opportunity cost of the labor supplied to the firm, thez desand is a very noisy signal and the degree of offset (measured by our $\bar{I}(x)$ ) is relatively weak. As perceived at the level of the firm, where recessions are just one of many sources of fluctuations, the inefficiency is fairly sall, but in the aggregate, where only aggregate fluctuations are visible, this limitation becomes important. A recession, in this view, is treated by irrss as no more than another reduction in demand for which a reduction in eجployment is the efficient response. Within the framework of employment-contingent bargains, there is no way to provide employers with a separate ircentive to stabilize employment in the face of an economy-wide reduction in desand. 
VIII. Goncluding remarks

We conclude by summarizing the explanations provided by our theory of the four puzzling features of collective bargaining listed at the outset:

1. Absence of contingencies on outside variables. Moral hazard and imperfect measurement limit contingencies based on outside variables. Further, contingency on the level of employment is such a powerful tool that it dominates outside contingencies.

2. Unilateral determination of employment by management. This is the central feature of employment-contingent contracts. The compensation rule makes labor approximately indifferent among alternative levels of employment, so there is little or no disagreement with management's choice. Neither management nor labor has an important incentive to default on the contract.

3. Periodic renegotiation of contracts. Changes in the opportunity cost of labor not predictable from changes in demand generate cumulative inefficiencies that can be relieved only by renegotiation.

4. Irrelevance of the current state of demand in collective bargaining. Employment-contingent contracts provide a complete mechanism for taking account of unexpected shifts in demand. Both parties are satisfied with the current level of employment if there have been no unexpected shifts on the supply side, no matter what is the level of demand. Only supply issues are sorted out in collective bargaining. This explains the paradox of large increases in wage schedules emerging from collective bargaining that takes place at a time of depressed employment. Labor's conventional justification for these increases - that wages elsewhere have risen substantially -- is exactly supported by our analysis. 


\section{Append 1x}

Efficient wage bargains when the opportunity cost of 1abor depends on income

A more general description of preferences would make the opportunity cost of labor depend on the overall level of well-being, $u$, according to a function $V(L, u, z)$. Well-being depends on income from sources other than employment of union members. Further, in accordance with the 1ife cyclepermanent income hypothesis, $u$ should reflect expectations of future earnings as well as the effect of the current contract. In the absence of demand and supply fluctuations, the basic condition for efficiency is

$$
R^{n}(L)=v_{1}(L, u)
$$

$\left(v_{1}\right.$ is the derivative of $v$ with respect to its first argument.) The contract curve is no longer a vertical line in the L-B diagram of Figure 1, but presumably slopes downward, assuming that the marginal opportunity cost of work is higher at higher levels of well-being. The efficient compensation rule is defined implicitly by

$$
B^{0}(L)=V_{1}(L, g(L, B(L)))
$$

an ordinary differential equation. Here $g(L, B)$ is the level of well-being achieved when work is $L$ and compensation is $B$.

With random demand and supply shifts $x$ and $z$, a fully contingent contract providing compensation $B(x, z)$ is efficient if

$$
\frac{R(L, x)}{\partial L}=V_{1}(L, g(L, B(L), z), z)
$$

for a11 $x$ and $z$. 
Then we can formalize the impossibility of an ideal compensation rule:

Theorem: Suppose that all of the second derivatives of $R$ and $V$ are continuous, that both $\mathrm{x}$ and $\mathrm{z}$ can vary within some rectangular region $\mathrm{a}_{1} \leqq \mathrm{x} \leqq \mathrm{a}_{2}$ and $\mathrm{b}_{1} \leqq \mathrm{z} \leqq \mathrm{b}_{2}$, and that the disturbances matter within this region in that $\partial^{2} R / \partial L \partial x>0$ and $\partial^{2} V / \partial L \partial z>0$. Suppose further that the marginal revenue schedule slopes downward: $\partial^{2} R / \partial L^{2}<0$ and nonwork is a normal good $\frac{\partial V_{1}}{\partial L}+\frac{\partial V_{1}}{\partial g} \frac{\partial g}{\partial L} \geqq 0$. Then there is no compensation rule for which

$$
\frac{\partial R}{\partial L}=B^{\prime}(L)
$$

and

$$
\frac{\partial V}{\partial L}=B^{\prime}(L)
$$

for all values of $x$ and $z$ in the region.

Proof: Suppose there were such a B(L). Then:

$$
\begin{aligned}
& \frac{\partial R(L, x)}{\partial L}=B^{\prime}(L) \text { makes } L \text { a function of } x \text {, with } \frac{\partial L}{\partial x} \neq 0 \\
& V_{1}(L, g(L, B(L), z), z)=B^{\prime}(L) \text { makes } L \text { a function of } z \text {, with } \\
& \frac{\partial L}{\partial z} \neq 0
\end{aligned}
$$

$$
\begin{aligned}
& \frac{\partial^{2} R}{\partial L^{2}} \frac{\partial L}{\partial z}=B^{\prime \prime}(L) \frac{\partial L}{\partial z} \text {. But since } \frac{\partial L}{\partial z} \neq 0, B^{\prime \prime}(L)=\frac{\partial^{2} R}{\partial L^{2}}<0 \\
& \left(\frac{\partial V_{1}}{\partial L}+\frac{\partial V_{1}}{\partial u} \frac{\partial g}{\partial L}+\left(\frac{\partial g}{\partial B} B^{\prime}(L)\right)\right) \frac{\partial L}{\partial x} \text {. But since } \frac{\partial L}{\partial x} \neq 0, \\
& B^{\prime \prime}(L)=\frac{\partial V_{1}}{\partial L}+\frac{\partial V_{1}}{\partial u}\left(\frac{\partial g}{\partial L}+\frac{\partial g}{\partial B} B^{\prime}(L)\right) \geqslant 0, \text { a contradiction. }
\end{aligned}
$$




\section{References}

Costas Âzariadis, "Implicit Contracts and Underemployment Equilibria," J. Po1. Econ, Dec。1975, 83, 1183-1202。 , "Escalator Clauses and the Allocation of Cyclical Risks," 1977 , forthcoming, J.Econ。Th.

Martin Neil Baily, "Wages and Employment under Uncertain Demand," Rev. Econ. Stud., Jan. 1974, XLI, 37-50.

Robert J. Barro, "Long-term Contracting, Sticky Prices, and Monetary Policy," J. Mon. Econ., Ju1. 1977, 3, 305-316.

Guillermo A. Calvo and Edmund S. Phelps, "Employment Contingent Wage Contracts," in K. Brunner and A. Meltzer (eds.), Stabilization of the Domestic and International Economy, Carnegie-Rochester Conference Series on Public Policy, $\underline{5}, 1977,160-168$.

Martin S. Feldstein, "The Importance of Temporary Layoffs: An Empirical Analysis," Brookings Papers on Economic Activity, 3:1975, 725-744. Stanley Fischer, "Long-term Contracts, Rational Expectations, and the Optimal Money Supply Rule," J. Polit. Econ.; Feb.1977, 85, 191-205.

Donald F. Gordon, "A Neo-Classical Theory of Keynesian Unemployment," in K. Brunner and A. Meltzer (eds.), The Phillips Curve and Labor Markets, Carnegie-Rochester Conference Series on Public Policy, 1 , 1975, 65-97. Herschel I. Grossman, "Risk Shifting and Reliability in Labor Markets," Scand. J. Econ, $1977: 2$, 79, 187-209. , "Risk Shifting, Layoffs, and Seniority," Brown University, Nov。1976.

Robert E. Hall, "The Rigidity of Wages and the Persistence of Unemployment," Brookings Papers on Economic Activity, 2:1975, 301-335. 
Wassily Leontief, "The Pure Theory of the Guaranteed Annual Wage Contract," J. Polit. Econ., Feb. 1946, 56, 76-79.

David Lilien, The Cyclical Pattern of Temporary Layoffs in United States

Manufacturing, Ph.D. dissertation, Dept. of Economics, MIT, Aug. 1977. George de Menil, Bargaining: Monopoly Power versus Union Power, MIT Press, 1971.

Edmund S. Phelps, "Indexation Issues: A Comment on the Blinder and Fischer Papers," in K. Brunner and A. Meltzer (eds.), Stabilization of the Domestic and International Economy, Carnegie-Rochester Conference Series on Public Policy, $\underline{5}, 1977,149-159$.

Edmund S. Phelps and John B. Taylor, "Stabilizing Powers of Monetary Policy under Rational Expectations," J. Polit. Econ., Feb. 1977, 85, 163-190. Herbert A. Simon, Models of Man, New York, 1957. 


\section{Footnotes}

†This research was supported by the National Science Foundation. We are grateful to Jerome Culp, Avinash Dixit and Jeffrey Harris for useful suggestions.

*Stanford University and University of California, San Diego.

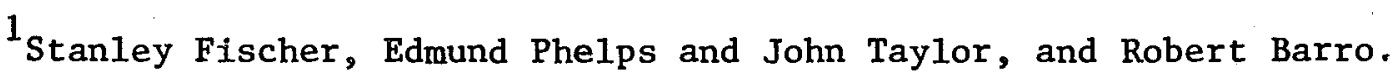

${ }^{2}$ Costas Azariadis 1975, 1977, Martin Baily, Donald Gordon, Herschel Grossman 1976, 1977, Phelps and Guillermo Calvo, and Phelps.

${ }^{3}$ In general, $V(L)$ should depend on wealth as well as employment. This dependence complicates the analysis without changing its character, and is deferred to the Appendix.

${ }^{4}$ The fact that the contract curve is vertical is a consequence of our assumption that the marginal opportunity cost of labor is independent of wealth and so is unaffected by the level of compensation. Again, see the Appendix for the more general case.

${ }^{5}$ George de Menil presents a complete discussion with many references. ${ }^{6}$ These limitations on contingent labor contracts, especially moral hazard, are discussed by Phelps and Calvo and by Phelps. In this paper., we do not present an extended justification for the assumption that contracts are not contingent, but rather pursue the implications of the assumption. In our view, it is still an unsettled question why contingencies are so rare.

${ }^{7}$ Again, this type of contingency is discussed by Calvo and Phelps. ${ }^{8}$ An interesting discussion of this problem appears in Herbert Simon, Chapter 11. Simon asks under what conditions labor will permit management to make a unilateral employment decision in exchange for a lump-sum wage payment. He does not consider the generalization where management makes the employment decision subject to a more general compensation rule. 
${ }^{9}$ In the usual contingent contract of the kind studied by Azariadis (1975) for example, optimization is prohibited. However, the limited ability of employers to enforce the terms of an employment contract against workers makes it possible for workers to default by quitting, as discussed by Grossman. Under the type of contract considered here, workers never have an economic incentive to quit.

${ }^{10}$ Here we depart from Calvo and Phelps. They define the preferred contract as the optimal compromise between the goals of efficiency and insurance. The compromise is necessary because of the limited power of the employment contingency. However, under the assumptions we use in the body of the paper, the efficient contract also provides optimal insurance. The effect of modifying the assumptions is discussed in the Appendix. We will return briefly to the insurance issue at the end of the paper.

${ }^{11}$ Under the fixed wage contract that is studied in the pioneering work of Baily and Azariadis, the level of employment is made contingent on an outside measure of demand. Lower levels of employment are desirable under that type of contract when demand is low if labor values its time. The novel feature here and in Calvo and Phelps is to make management responsible for setting employment and to use profit maximization ex post as the mechanism for achieving the efficient level of employment.

${ }^{12}$ In the United States, there are legal restrictions on the enforcement of contracts lasting more than three years.

${ }^{13}$ See Martin Feldstein and David Lilien.

${ }^{14}$ Some premiums are required by 1 law.

${ }^{15}$ For a discussion of this point, see Robert Hall. 